\title{
Giant Cystic Intradural Lumbosacral Schwannoma: Is Stabilization Necessary?
}

\author{
Jeffrey S. Wilkinson, Sumeer A. Mann, Christopher A. Robinson, Daryl R. Fourney
}

Can. J. Neurol. Sci. 2010; 37: 535-538

Schwannomas are relatively common in neurosurgical practice, accounting for approximately $25 \%$ of all primary spinal tumors $^{1}$. The vast majority of spinal schwannomas are small, well-circumscribed, intradural, extradural or combined intradural-extradural lesions. Lumbosacral schwannomas may attain significant size before the development of painful symptoms or neurologic deficit, owing to slow growth of the tumor, mobility of the nerve roots, and wide capacity of the spinal canal. There are more than 20 reported cases of giant schwannomas involving the cauda equina - most of them intrasacral $^{2}$.

Degenerative changes such as hemorrhage, calcification, or fibrosis are frequently seen in schwannomas, but cystic changes are rare. Cystic schwannomas have been reported in the orbit ${ }^{3}$, olfactory groove ${ }^{4}$, cavernous sinus ${ }^{3,5}$, ventricular system ${ }^{6}$, cervical plexus ${ }^{7}$ and pancreas $^{8}$. Within the spine, there are at least ten previously reported cases of schwannomas with a large cyst ${ }^{3,6,9-12}$.

The combination of a giant intradural lumbosacral schwannoma with a significant cystic component is exceedingly rare. To the best of our knowledge, there are only two previously reported cases ${ }^{2,3}$. The case reported by Jaiswal et $\mathrm{al}^{3}$ had minimal vertebral erosion; however, the case reported by Kagaya et $\mathrm{al}^{2}$ has extensive vertebral body scalloping, L3-S1. Therefore, an extensive stabilization was performed, which included L2-ilium fixation and vertebral body reconstruction at L3-S1 with a ceramic implant. We report an additional case and discuss (1) the differential diagnosis of cystic lumbosacral masses and (2) the difficulty of obtaining spinal stabilization in the presence of significant bony erosion by tumor.

\section{Case Report}

Presentation: A 38-year-old woman with a longstanding ( $>10$ years) history of lower back pain presented with an increase in back pain and right-sided sciatica over one month. She was referred to our clinic after x-ray films showed scalloping of the vertebral bodies at L4 and S1 (Figure 1). There was no history of bladder or bowel dysfunction. On examination, she had numbness to pin prick in an L4-S1 distribution on the right. There was weakness and mild wasting of her right hamstring, tibialis anterior, and gastrocnemius muscles (grade 34/5). The right ankle reflex was absent.

Imaging: Computed tomogram images best demonstrated the erosive scalloping of the L3-S1 vertebral bodies (Figure 2). Magnetic resonance imaging (MRI) (Figure 3) showed an L3-5 intradural mass, hyperintense on $\mathrm{T} 2$ and hypointense on $\mathrm{T} 1$, demonstrating avid contrast enhancement. At L4, almost 2/3rds of the vertebral body was eroded and the pedicles were thinned to 1-2 mm diameter (Figure 2). At L5-S2, there was a distal rimenhancing cystic collection that eroded into the posterior third of the $\mathrm{S} 1$ vertebral body.

Operation: An L3-5 laminectomy was performed. The laminae, the ligamentum flavum and the dura were all paper thin and adherent to each other, consistent with slow growth of the mass and erosion of these tissues over time. The nerve roots were pushed dorsally by the tumor, and in places they were somewhat adherent to the mass. Using microsurgical technique, we were able to dissect the cauda equina free of the tumor. Nerve root function was monitored by spontaneous and evoked electromyography. The facet joints and capsules were preserved. The dura was reconstructed with a collagen matrix graft (DuraGen, Integra Lifescience Corp., Plainsboro, New Jersey). Since the pedicles of L3-S1 had been eroded by the tumor, an instrumented stabilization would have required extensive fixation of the upper lumbar levels to the ilium. Given the patient's young age, slender body habitus, preservation of lumbar lordosis, relatively intact facet joints, and limited disc degeneration, we decided not to perform a fusion and instead followed her closely for evidence of instability.

Pathology: Histology revealed a conventional schwannoma (WHO grade I), with both Antoni A and B growth patterns present (Figure 4). Verocay bodies were commonly seen, and the tumor cells were immunopositive for S100 protein antibody. Proliferative activity was minimal and necrosis was absent.

Postoperative Course: The right foot drop was worse postoperatively (grade 1/5), and the patient was fitted with an ankle foot orthosis (AFO). Although she did not complain of a low-pressure headache, she developed a postoperative pseudomeningocele that subsided spontaneously over three weeks. Magnetic resonance imaging showed a small amount of residual tumor along the scalloped edge of the tumor bed within the L4 vertebral body (Figure 5).

At 21 months postoperatively, there has been no progression of the residual disease. She continues to have difficulty with urinary retention, requiring occasional in-and-out catheter-

From the Division of Neurosurgery and Department of Pathology and Laboratory Medicine, University of Saskatchewan, Saskatoon, Saskachewan, Canada.

Received November 30, 2009. Final Revisions Submitted February 24, 2010. Correspondence to: Daryl R. Fourney, Division of Neurosurgery, University of Saskatchewan, Royal University Hospital, 103 Hospital Drive, Saskatoon, Saskatchewan, S7N 0W8, Canada. 


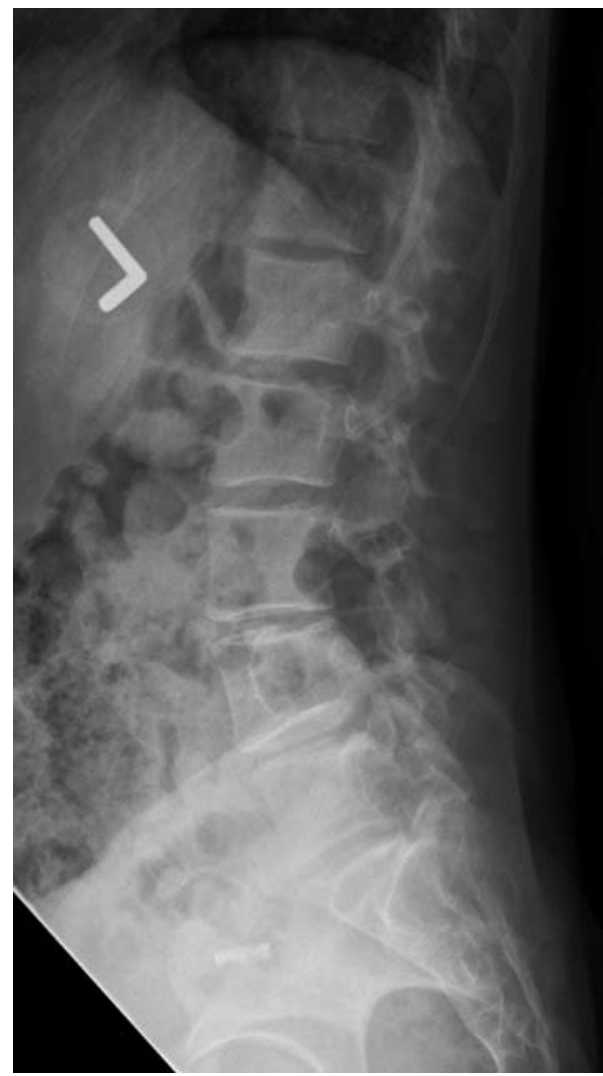

Figure 1: Lateral lumbar X-ray film demonstrates scalloping of the posterior vertebral body of L3-S1.

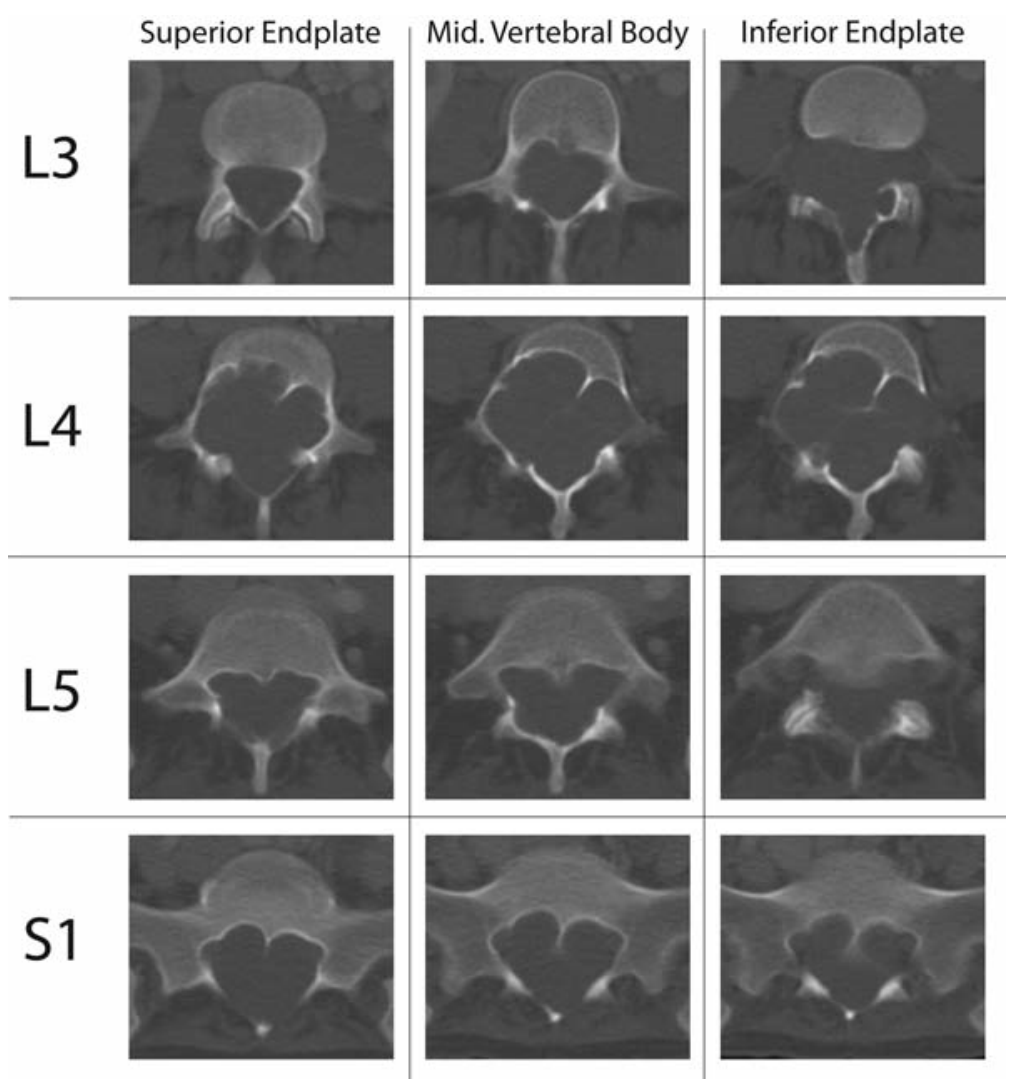

Figure 2: Pre-operative axial CT imaging of the lower lumbar and sacral spine (L3S1), showing extensive bony erosion of the spinal canal at the level of the superior, middle, and inferior endplates. ization. She has no back pain and full range of motion. X-ray films show maintenance of normal alignment and stability on flexion/extension views (Figure 6). Her foot drop has improved such that she no longer wears the ankle foot orthosis.

\section{Discussion}

Confusion exists regarding the term "giant" schwannoma. Sridhar et $\mathrm{al}^{13}$ classified giant schwannomas as those that extend over more than two vertebral levels (Type II), those with an extraspinal extension of more than $2.5 \mathrm{~cm}$ (giant dumbbell, Type $\mathrm{IVb}$ ), and those lesions that erode the vertebral bodies and extend laterally and posteriorly into the myofascial planes (giant invasive, Type V). The present case corresponds to Type $\mathrm{V}$ in this classification. There are at least 20 published case reports of Type V lesions, almost exclusively located in the lumbosacral spine $^{2,3,13}$. In almost every reported case, there is a long history of lower back pain that may have been present for several years ${ }^{14}$. Most patients have radicular symptoms (motor or sensory loss); however, given the slow growth of the tumor, and the mobility of the cauda equina, neurological deficits may be minimal in comparison to the size of the mass ${ }^{14}$.

Histological variants of schwannoma have been described and include cellular ${ }^{15}$, melanotic ${ }^{16}$ and plexiform ${ }^{17}$ subtypes. Ancient schwannoma is a rare variant characterized by

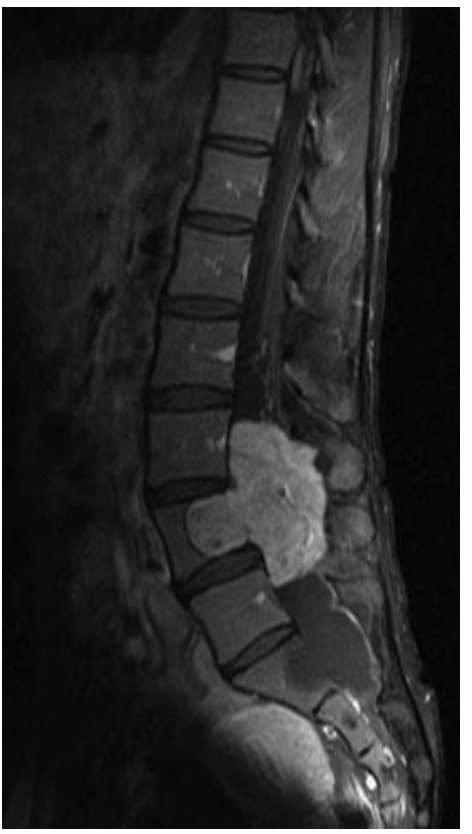

Figure 3: Pre-operative T1 weighted, gadolinium contrast-enhanced sagittal MRI demonstrates homogeneous enhancement of the L3-5 intradural mass and a distal intradural cyst with apparent inferior rim enhancement. There is erosion of the L4 and S1 vertebral bodies and the posterior elements of L3-5. 
degenerative changes including cyst formation, calcification, hemorrhage, fibrosis and cytologic atypia ${ }^{18}$. Cystic degeneration is usually seen in only a small part of ancient schwannomas. Predominantly cystic schwannomas have been reported throughout the nervous system ${ }^{19}$ and at other sites ${ }^{8}$. In a review of the literature, we identified ten cases of cystic schwannoma of the spine ${ }^{3,6,9-12}$. Cystic changes are hypothesized to occur due to mucinous degeneration, ischemic necrosis, hemorrhage, and the formation and subsequent coalescence of microcysts. In the present case, there was no evidence of necrosis on histopathology.

The combination of a giant invasive schwannoma with a significant cystic component is extremely rare, with only two previously reported cases to our knowledge ${ }^{2,3}$.

In formulating a differential diagnosis we considered any intradural neoplasms associated with slow growth, given the scalloping of the vertebral bodies and enlargement of the spinal canal $^{20,21}$. The patient had no history of neurofibromatosis. The differential diagnosis for our patient included schwannoma, cystic neurofibroma ${ }^{10}$, myxopapillary ependymoma ${ }^{22}$, cystic meningioma ${ }^{23}$, and cystic teratoma ${ }^{24}$. Although there are no pathognomic radiographic findings for schwannoma, rim enhancement of the cystic potion of this intradural extramedullary tumor is highly suggestive of the diagnosis ${ }^{25}$.

There is some controversy over the need to completely resect giant intradural schwannomas ${ }^{2,26,27}$. In an incomplete resection, some progression of residual schwannoma is quite likely, although it may take several years for a symptomatic recurrence to develop ${ }^{14}$. The surgeon needs to balance the risk of neurological deficit with an aggressive resection versus the probability of early symptomatic recurrence if considerable residual disease is left behind. Giant schwannomas may envelope the nerve roots ${ }^{28}$. In the current case, most of the cauda equina was pushed dorsally by the tumor, although several nerve roots were adherent to it. Using microsurgical techniques, we were able to obtain a gross total resection; however, the
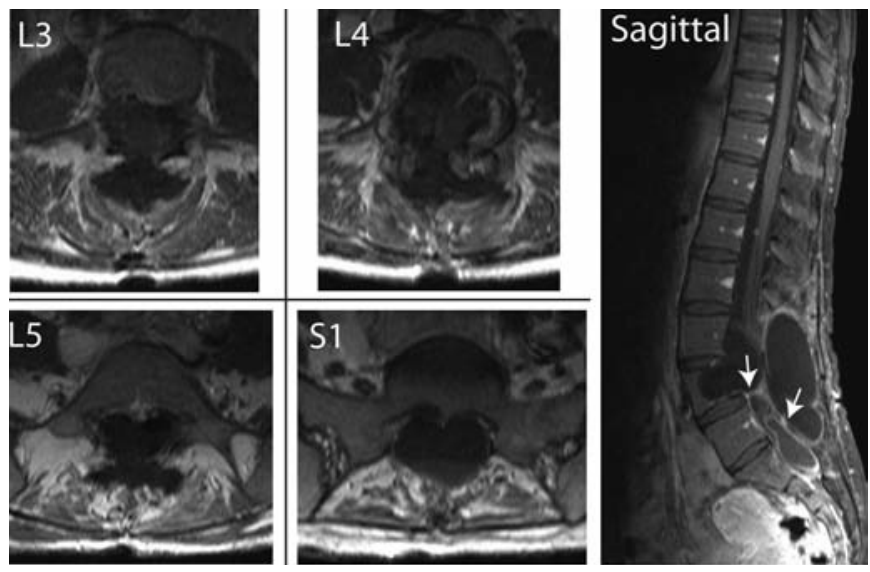

Figure 5: One-year post-operative T1 weighted, gadolinium contrastenhanced sagittal MRI and axial cuts at L3-S1 show resection of the tumor, although there is some persistent rim enhancement within the L4 vertebral body and the caudal cyst wall (white arrows).

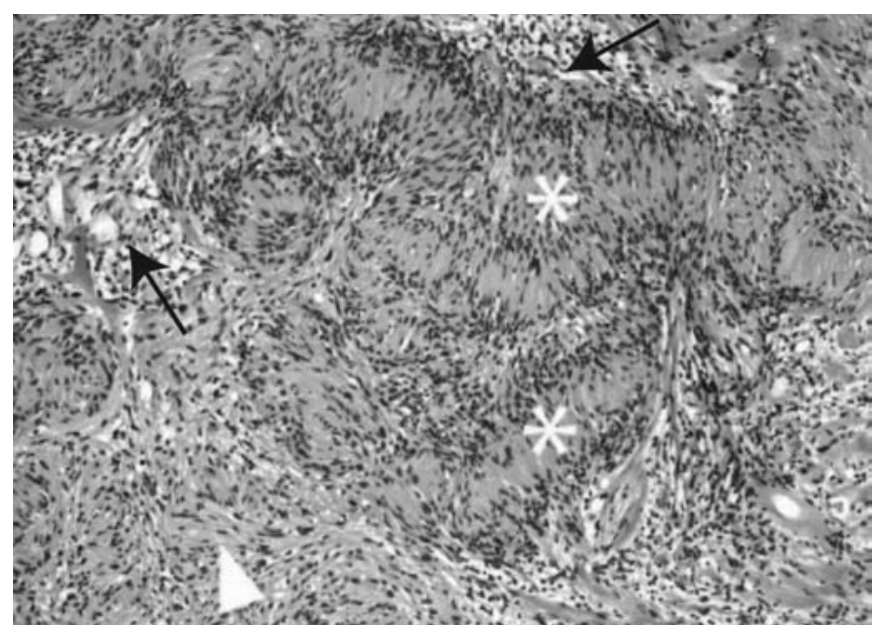

Figure 4: Several Verocay bodies (asterisks) with nuclear palisading, and adjacent solid Antoni $A$ (white triangle) and loosely textured Antoni $B$ (black arrows) tissue. Hematoxylin-eosin, original magnification $X$ 100.

postoperative MRI showed some persistent enhancement along the scalloped edge of the L4 vertebral body as well as along the sacral tumor cyst wall. Our patient will have to be monitored regularly with MRI for recurrence.

Ensuring spinal stabilization is an important goal in the treatment of giant lumbosacral tumors. Most recently reported cases have been treated with a variety of stabilization techniques ${ }^{2,29}$. Sridhar et al ${ }^{13}$ recommended that stabilization be performed whenever $25 \%$ of the vertebral body is compromised. Although the vertebral body erosion in the present case was much greater, we decided not to perform a fusion. There were several reasons that factored into our decision. The tumor had eroded much of the bone and the patient had no loss of vertebral alignment. The laminae, which were the only bony structures we removed to access the tumor, were already paper-thin. The slow process of bone remodeling likely caused the remaining L4 vertebral body to assume greater stability. In addition, our patient was young with a thin frame and had good preservation of the lumbar lordosis, facet joints and intervertebral discs.

There are several benefits to not placing instrumentation in this particular case: (1) instrumentation hinders subsequent imaging surveillance for recurrence; (2) our approach does not preclude subsequent stabilization in the unlikely even that the patient demonstrates instability over time; (3) wound complications and large pseudomeningoceles may be better avoided with this staged approach by allowing reconstitution of the thecal sac following the index procedure prior to more extensive dissection for stabilization.

We continue to follow this patient clinically and radiologically for evidence of recurrence or instability, although she is now 21 months post-surgery without evidence of either.

We have presented an exceedingly rare case of giant invasive cystic schwannoma treated successfully with microsurgical resection. In determining the need for postoperative stabilization, the surgeon needs to consider other factors besides the obvious extent of bony erosion. 


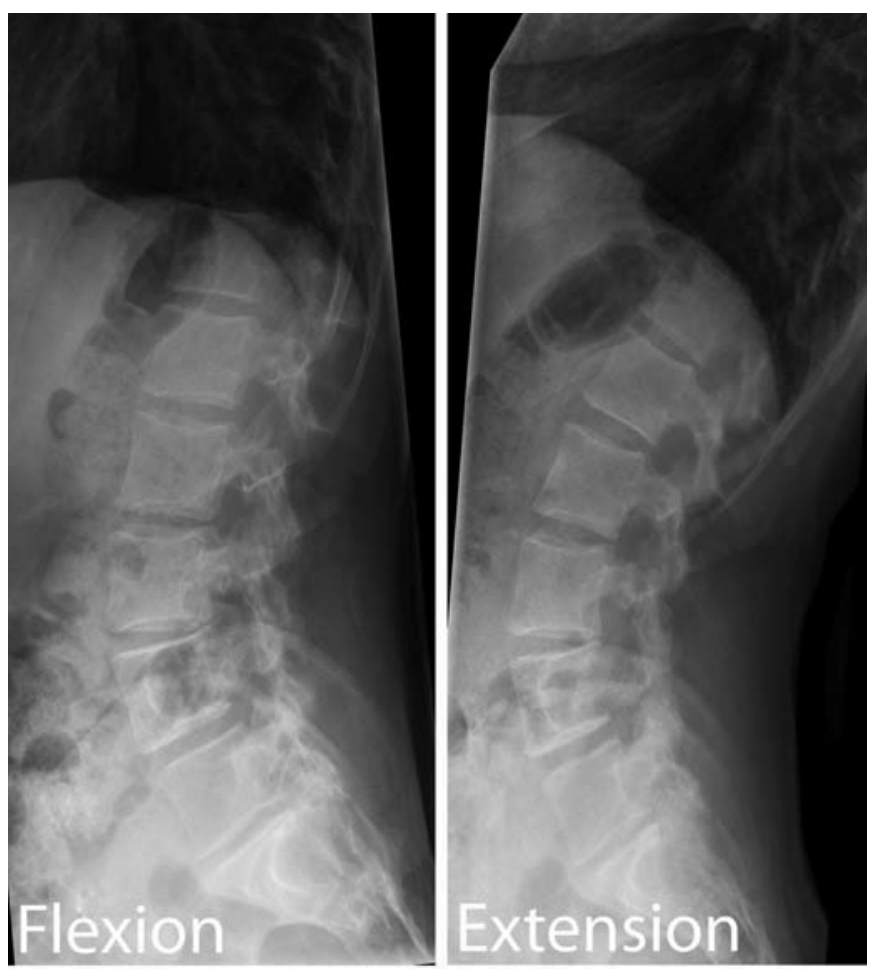

Figure 6: Lateral flexion/extension radiographs of the lumbar spine 21 months post-operatively.

\section{REFERENCES}

1. Louis DN, Ohgaki H, Wiestler OD, Cavenee WK, Burger PC, Jouvet A, et al. The 2007 WHO classification of tumours of the central nervous system. Acta Neuropathol. 2007 Aug;114(2): 97-109.

2. Kagaya H, Abe E, Sato K, Shimada Y, Kimura A. Giant cauda equina schwannoma. A case report. Spine. 2000 Jan 15;25(2): 268-72.

3. Jaiswal A, Shetty AP, Rajasekaran S. Giant cystic intradural schwannoma in the lumbosacral region: a case report. J Orthop Surg (Hong Kong). 2008 Apr;16(1):102-6.

4. Daglioglu E, Okay O, Dalgic A, Albayrak AL, Ergungor F. Cystic olfactory schwannoma of the anterior cranial base. Br J Neurosurg. 2008 Oct;22(5):697-9.

5. Conti P, Pansini G, Mouchaty H, Capuano C, Conti R. Spinal neurinomas: retrospective analysis and long-term outcome of 179 consecutively operated cases and review of the literature. Surg Neurol. 2004 Jan;61(1):34-43; discussion \#4.

6. Borges G, Bonilha L, Proa M, Jr., Fernandes YB, Ramina R, Zanardi $\mathrm{V}$, et al. Imaging features and treatment of an intradural lumbar cystic schwannoma. Arq Neuropsiquiatr. 2005 Sep;63 (3A):681-4

7. Buchanan MA, Williams SM, Hellquist H, Innes AJ. Cystic schwannoma of the cervical plexus masquerading as a type II second branchial cleft cyst. Eur Arch Otorhinolaryngol. 2009 Mar;266(3):459-62.

8. Tofigh AM, Hashemi M, Honar BN, Solhjoo F. Rare presentation of pancreatic schwannoma: a case report. J Med Case Reports. 2008;2:268.

9. Akhaddar A, Ajja A, Albouzidi A, Elmostarchid B, Boucetta M. Cystic schwannoma of the cauda equina mimicking hemangioblastoma. Neurochirurgie. 2008 Apr;54(2):101-3.
10. Parmar H, Patkar D, Gadani S, Shah J. Cystic lumbar nerve sheath tumours: MRI features in five patients. Australas Radiol. 2001 May;45(2):123-7.

11. Shen WC, Lee SK, Chang CY, Ho WL. Cystic spinal neurilemmoma on magnetic resonance imaging. Neuroradiology. 1992;34(5):447-8.

12. Shiono T, Yoshikawa K, Iwasaki N. Huge lumbar spinal cystic neurinomas with unusual MR findings. AJNR Am J Neuroradiol. 1995 Apr;16 Suppl 4:881-2.

13. Sridhar K, Ramamurthi R, Vasudevan MC, Ramamurthi B. Giant invasive spinal schwannomas: definition and surgical management. J Neurosurg. 2001 Apr;94 Suppl 2:210-5.

14. Bhatia S, Khosla A, Dhir R, Bhatia R, Banerji AK. Giant lumbosacral nerve sheath tumors. Surg Neurol. 1992 Feb;37(2): $118-22$

15. Woodruff JM, Godwin TA, Erlandson RA, Susin M, Martini N. Cellular schwannoma: a variety of schwannoma sometimes mistaken for a malignant tumor. Am J Surg Pathol. 1981 Dec;5 (8):733-44.

16. Font RL, Truong LD. Melanotic schwannoma of soft tissues. Electron-microscopic observations and review of literature. Am J Surg Pathol. 1984 Feb;8(2):129-38.

17. Woodruff JM, Marshall ML, Godwin TA, Funkhouser JW, Thompson NJ, Erlandson RA. Plexiform (multinodular) schwannoma. A tumor simulating the plexiform neurofibroma. Am J Surg Pathol. 1983 Oct;7(7):691-7.

18. Saiful Azli MN, Abd Rahman IG, Md Salzihan MS. Ancient schwannoma of the conus medullaris. Med J Malaysia. 2007 Aug;62(3):256-8

19. Kleihues P, Louis DN, Scheithauer BW, Rorke LB, Reifenberger G, Burger PC, et al. The WHO classification of tumors of the nervous system. J Neuropathol Exp Neurol. 2002 Mar;61(3): 215-25; discussion 26-9.

20. Hung CH, Tsai TH, Lieu AS, Lin CL, Lee KS, Hwang SL, et al. Giant invasive schwannoma of cauda equina with minimal neurologic deficit: a case report and literature review. Kaohsiung J Med Sci. 2008 Apr;24(4):212-7.

21. Osborn RE, DeWitt JD. Giant cauda equina schwannoma: CT appearance. AJNR Am J Neuroradiol. 1985 Sep-Oct;6(5):835-6.

22. Fourney DR, Prabhu SS, Cohen ZR, Rhines LD, Gokaslan ZL. Thoracolumbopelvic stabilization for the treatment of instability caused by recurrent myxopapillary ependymoma. J Spinal Disord Tech. 2003 Feb;16(1):108-11.

23. Hwang SL, Liu CS, Su YF, Shen WJ, Chuo CY, Liu GC, et al. Giant nondural-based cauda equina meningioma with multiple cysts. J Neurooncol. 2005 Sep;74(2):173-7.

24. Fernandez-Cornejo VJ, Martinez-Perez M, Polo-Garcia LA, Martinez-Lage JF, Poza M. Cystic mature teratoma of the filum terminale in an adult. Case report and review of the literature. Neurocirugia (Astur). 2004 Jun;15(3):290-3.

25. Friedman DP, Tartaglino LM, Flanders AE. Intradural schwannomas of the spine: MR findings with emphasis on contrast-enhancement characteristics. AJR Am J Roentgenol. 1992 Jun;158(6):1347-50.

26. Iwasaki M, Nakamura K, Takeshita K, Kawaguchi H, Akune T, Hoshino Y. Surgical management of giant schwannoma in the lumbosacral region. J Spinal Disord. 1998 Oct;11(5):444-7.

27. Kim P, Ebersold MJ, Onofrio BM, Quast LM. Surgery of spinal nerve schwannoma. Risk of neurological deficit after resection of involved root. J Neurosurg. 1989 Dec;71(6):810-4.

28. Wu WQ. Management of two giant neurilemomas of the cauda equina. South Med J. 1980 Mar;73(3):386-8.

29. Saito T, Shimode M, Azuma S, Seichi A. Giant schwannoma of the cauda equina with dural ectasia: a case report. J Orthop Sci. 2004;9(6):635-7 